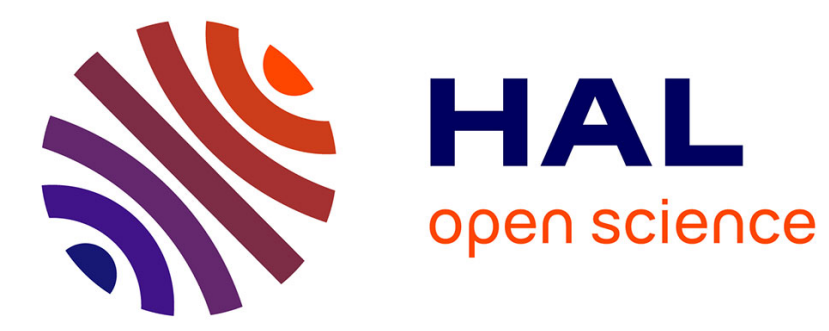

\title{
Rayleigh wave phase velocity and error maps up to the fifth overtone
}

\author{
Stephanie Durand, Eric Debayle, Yanick Ricard
}

\section{To cite this version:}

Stephanie Durand, Eric Debayle, Yanick Ricard. Rayleigh wave phase velocity and error maps up to the fifth overtone. Geophysical Research Letters, 2015, 42 (9), pp.3266-3272. 10.1002/2015GL063700 . hal-02944867

\section{HAL Id: hal-02944867 \\ https://hal.science/hal-02944867}

Submitted on 21 Sep 2020

HAL is a multi-disciplinary open access archive for the deposit and dissemination of scientific research documents, whether they are published or not. The documents may come from teaching and research institutions in France or abroad, or from public or private research centers.
L'archive ouverte pluridisciplinaire HAL, est destinée au dépôt et à la diffusion de documents scientifiques de niveau recherche, publiés ou non, émanant des établissements d'enseignement et de recherche français ou étrangers, des laboratoires publics ou privés. 


\section{Geophysical Research Letters}

\section{RESEARCH LETTER \\ 10.1002/2015GL063700

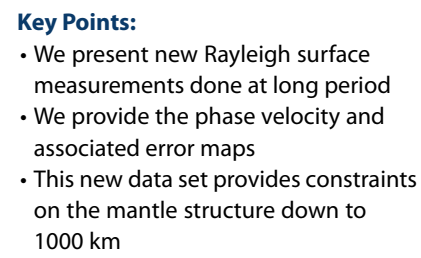

Correspondence to:

S. Durand,

stephanie.durand@ens-lyon.fr

\section{Citation:}

Durand, S., E. Debayle, and Y. Ricard (2015), Rayleigh wave phase velocity and error maps up to the fifth overtone, Geophys. Res. Lett., 42, 3266-3272, doi:10.1002/2015GL063700.

Received 2 MAR 2015 Accepted 9 APR 2015 Accepted article online 16 APR 2015 Published online 7 MAY 2015

\section{Rayleigh wave phase velocity and error maps up to the fifth overtone}

\author{
Stéphanie Durand ${ }^{1}$, Eric Debayle ${ }^{1}$, and Yanick Ricard ${ }^{1}$ \\ ${ }^{1}$ Laboratoire de Géologie de Lyon-Terre, Planète, Environnement, CNRS UMR 5276, École Normale Supérieure de Lyon, \\ Université de Lyon, Université Claude Bernard Lyon 1, Villeurbanne, France
}

\begin{abstract}
We present a global data set of phase velocity maps for Rayleigh waves, with their errors. These maps are obtained from the tomographic inversion of phase velocity curves measured in the period range 40-250 s by Debayle and Ricard (2012), completed with new measurements at longer periods, between 150 and $360 \mathrm{~s}$. The full data set includes $\sim 22,000,000$ phase velocity measurements combined to build 60 phase velocity maps covering the period range 40-360 s for the fundamental mode and up to the fifth overtone. Each phase velocity map is provided with its a posteriori error, resulting in a unique data set which can be combined with other seismic measurements (surface waves, normal modes, and body waves) in regional and global tomographic studies. A preliminary inversion of this data set shows that it provides constraints on the shear velocity structure down to $1000 \mathrm{~km}$ depth.
\end{abstract}

\section{Introduction}

Global seismic models suffer from a decrease of resolution in the transition zone located between $\sim 400$ and $\sim 1000 \mathrm{~km}$ depth. Except in very specific regions, like subduction zones [e.g., Ritsema et al., 2004; Debayle et al., 2005], these depths are neither well sampled by the dominant fundamental mode of surface waves nor by teleseismic body waves. It is, however, possible to achieve a global coverage of the transition zone by extracting more information from surface waves.

A first possibility is to extend the analysis to longer periods. Most data sets derived from surface waves are fundamental mode dispersion curves measured at periods shorter than 200 s [Trampert and Woodhouse, 1995; Ekström et al., 1997; Ritzwoller and Levshin, 1998; Ekström, 2011; Visser et al., 2008; Burgos et al., 2014] which limits the penetration depth to $\sim 250-300 \mathrm{~km}$. It is, however, possible to increase the sensitivity to the transition zone by measuring the fundamental mode at larger periods up to $360 \mathrm{~s}$ [Nettles and Dziewonski, 2008].

A second possibility is to extract higher-mode information [e.g., Nolet, 1975; Cara, 1979]. Higher modes are difficult to use because they interfere in the time domain over a broad frequency range. A variety of methods for extracting higher-mode dispersion curves has been developed [Nolet, 1975; Cara, 1979; Cara and Lévêque, 1987; Stutzmann and Montagner, 1993; Beucler et al., 2003; van Heijst and Woodhouse, 1997; Ekström et al., 1997; Debayle, 1999; Yoshizawa and Kennett, 2002; Lebedev et al., 2005; Visser et al., 2007]. Those using a single seismogram [van Heijst and Woodhouse, 1997; Ekström et al., 1997; Debayle, 1999; Yoshizawa and Kennett, 2002; Lebedev et al., 2005] achieve the best coverage and have been used to build the most recent tomographic models [Ritsema et al., 2011; Debayle and Ricard, 2012; Shaeffer and Lebedev, 2013].

In this manuscript, Rayleigh wave seismograms are analyzed with the automated waveform inversion technique of Debayle [1999], modified by Debayle and Ricard [2012]. This waveform inversion is based on Cara and Lévêque [1987] and provides for a Rayleigh wave seismogram, an average 1-D velocity profile, a set of phase velocity dispersion curves, and their associated a posteriori errors. We obtain a database of Rayleigh wave dispersion curves for the fundamental and the five first overtones. For each mode and for each period, we have combined the measured phase velocities in a tomographic inversion to obtain phase velocity maps with their a posteriori errors. A posteriori errors provide an objective way to weigh our maps when combined with other seismic data sets in future global or regional tomographic studies. A preliminary inversion of our Rayleigh wave maps alone shows that they allow to constrain mantle shear velocities down to $1000 \mathrm{~km}$ depth.
C2015. American Geophysical Union. All Rights Reserved. 
Table 1. Summary of the Whole Data Set Indicating the Number of Phase Velocities Measured on the Raw Data Set and Selected to Build the Phase Velocity Maps

\begin{tabular}{lcccc} 
Mode & Period Range $(s)$ & $\begin{array}{c}\text { Number of Measured } \\
\text { Periods }\end{array}$ & $\begin{array}{c}\text { Number of Raw } \\
\text { Measurements }\end{array}$ & $\begin{array}{c}\text { Number of Selected } \\
\text { Measurements }\end{array}$ \\
\hline Fundamental mode & $40-360$ & 21 & $7,270,127$ & $1,559,939$ \\
First overtone & $40-240$ & 15 & $6,088,848$ & $1,159,831$ \\
Second overtone & $40-160$ & 11 & $3,838,851$ & 810,597 \\
Third overtone & $40-90$ & 7 & $2,608,403$ & 549,864 \\
Fourth overtone & $40-50$ & 3 & $1,117,887$ & 214,329 \\
Fifth overtone & $40-50$ & 3 & $1,117,887$ & 238,369 \\
Total & & 60 & $22,042,003$ & $4,532,929$ \\
\hline
\end{tabular}

\section{Data Sets}

We use a set of dispersion curves measured by Debayle and Ricard [2012] from 372,629 Rayleigh waveforms. Phase velocities were measured in the period range 40-250 s for the fundamental mode and up to the fifth overtone. In addition, we apply the same algorithm to 161,730 Rayleigh waveforms recorded for large events $\left(6.0<M_{w}<7.2\right)$ which excite surface waves at periods greater than $200 \mathrm{~s}$. These waveforms are modeled in the period ranges $120-360 \mathrm{~s}, 120-240 \mathrm{~s}$, and $120-180 \mathrm{~s}$ for the fundamental, first, and second higher modes, respectively.

The whole data set includes $\sim 22,000,000$ phase velocity measurements done on a total of 534,359 Rayleigh wave seismograms. A summary of the number of measurements done for each mode branch is given in Table 1. It is larger than previous Rayleigh wave data sets measured by van Heijst and Woodhouse [1999] or Visser et al. [2008]. It provides new fundamental and higher-mode measurements in the period range 120-360 s, which expands the fundamental mode study by Nettles and Dziewonski [2008]. It is comparable in size to the data sets of Shaeffer and Lebedev [2013] or Ritsema et al. [2011], but the modal and frequency contents differ. While Shaeffer and Lebedev [2013] analyze up to 14 higher modes in the period range 10-400 s, we limit the number of modes to six and the period range to 40-360 s (Figure 1) which should minimize possible biases due to off great circle propagation and mode coupling effects. In addition, this data set completes that of Ritsema et al. [2011] with measurements at longer periods, up to $360 \mathrm{~s}$, and up to the fifth overtone.

Figure 1 displays the mean phase velocities and the periods and modes for which measurements have been made. The mean phase velocities are, in general, slightly larger than preliminary reference Earth model (PREM) [Dziewonski and Anderson, 1981] (purple dashed curves). Part of this difference may be due to the fact that a

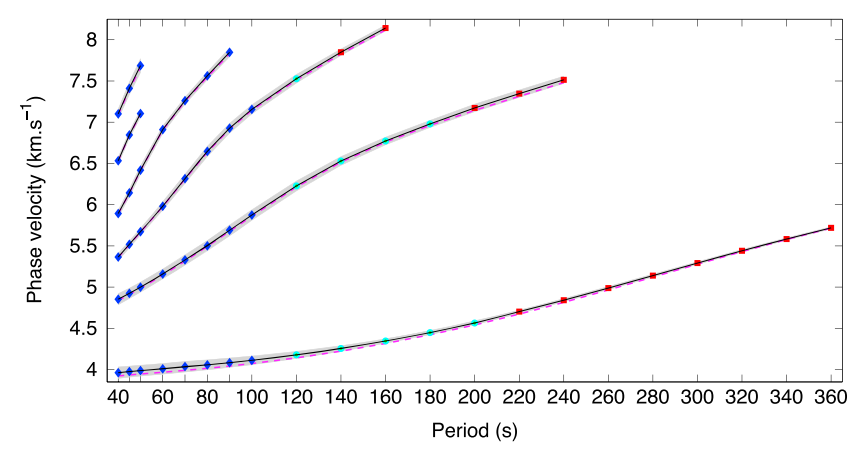

Figure 1. Average dispersion of our entire data set (black curves) with 1 standard deviation errors (gray areas). Dispersion curves are shown for the fundamental mode and the first five overtones. Blue diamonds, light blue circles, and red squares show periods and modes for which measurements are averaged over Debayle and Ricard's [2012] data set only, Debayle and Ricard's [2012] data set plus long-period measurements, and only long-period measurements, respectively. The dispersion of model PREM (purple dashed curves) is shown for comparison. All phase velocities are corrected from the physical dispersion due to attenuation [Kanamori and Anderson, 1977] using a reference period of $T=100 \mathrm{~s}$. 
large portion of our data set samples the thick and fast cratons of the Northern Hemisphere continents. The exact values used to plot Figure 1 are provided in supporting information Tables S1 and S2.

For each individual waveform, we extract the phase velocities for the fundamental mode and up to the fifth overtone and for a total of 60 periods using the iterative and nonlinear inversion scheme of Tarantola and Valette [1982]. Our approach to fit the waveform introduces a number of secondary observables [Cara and Lévêque, 1987]. This inversion is only weakly nonlinear, and we can approximate the a posteriori covariance matrix of our inversion at the last iteration. This processing step therefore extracts from each waveform up to 60 phase velocities with their uncertainties (the root square of the diagonal covariance matrix).

To decrease the number of data and improve its robustness, we cluster the seismic paths with close epicenters recorded at a given station [Debayle and Ricard, 2012]. We use a cluster radius of $400 \mathrm{~km}$ (i.e., close to the horizontal smoothing defined in section 3 ) and consider that the waves of a given cluster follow the same path and feel the same average dispersion between the epicenters and the station. Within each cluster, we select the best resolved phase velocity at each period and each mode, associated with the smallest a posteriori error and only when this a posteriori error is smaller than $80 \%$ of the a priori error. This path clustering allows us to restrict the whole data set to independent paths, to discard outliers, and decreases significantly the number of data and their associated uncertainties (see Table 1).

\section{Building Phase Velocity and Error Maps}

We combine the selected data (i.e., the phase velocities along seismics paths, measured for each mode and each period) using a continuous regionalization scheme [Tarantola and Valette, 1982; Montagner, 1986; Debayle and Sambridge, 2004]. We obtain smooth phase velocity maps by imposing correlations between neighboring points using a Gaussian a priori covariance function controlled by an horizontal correlation length, fixed to $400 \mathrm{~km}$. Increasing the horizontal correlation length leads to smoother tomographic images with lower amplitude anomalies, but the overall pattern of anomalies remains unchanged. An a priori model standard deviation controls the amplitude of the inverted model and is set to $0.05 \mathrm{~km} \mathrm{~s}^{-1}$, according to the expected variation range of the shear velocity in the upper mantle [Nishimura and Forsyth, 1989; Debayle and Ricard, 2012].

Figure 2 presents some examples of phase velocity (middle column) and error (right column) maps. First, the phase velocity pattern is in agreement with what is expected from the sensitivity kernels (Figure 2, left column). For instance, for the fundamental mode at $40 \mathrm{~s}$ (Figure 2, first row) which has a maximum of sensitivity around $70 \mathrm{~km}$ depth, the phase velocity map principally displays the surface tectonics. If we consider a longer period, $280 \mathrm{~s}$ (Figure 2, second row), the maximum of sensitivity is now in the transition zone and the presence of slabs become conspicuous. It can also be noted the similarity between the phase velocity maps of the fundamental mode at $40 \mathrm{~s}$ (Figure 2, first row), the third overtone at $90 \mathrm{~s}$ (Figure 2, fourth row), and the fifth overtone at $40 \mathrm{~s}$ (Figure 2, fifth row) which is related to a similar depth of maximum sensitivity. This reinforces the quality of the measurements. Concerning the error maps (Figure 2, right column), they are obtained from the diagonal of the a posteriori covariance matrix. They are normalized to the a priori model standard deviation of $0.05 \mathrm{~km} \mathrm{~s}^{-1}$. The shading is such that the best resolved regions are in black and the poorly resolved regions in white.

The whole data set (shear velocity kernels, phase velocity maps, error maps, and ray density maps) is presented in supporting information Figure S1. The error maps correlate with the ray density; the phase velocity is better constrained where the ray coverage is denser. Shear velocity sensitivity kernels show that our new data set modeled for large events at long periods (fundamental mode up to $360 \mathrm{~s}$ ) provides additional information on the shear velocity structure in the depth range $100-1000 \mathrm{~km}$.

\section{Depth Inversion}

The regionalization step leads to 60 maps of phase velocity and error (supporting information Figure S1) for the periods and modes given in Figure 1. We extract at each geographical point the ensemble of phase velocity measurements and their corresponding errors that are inverted to obtain 1-D depth-dependent $V_{s}$ profile. The juxtaposition of the $V_{s}$ profiles at each geographical point leads to a 3-D model of shear velocities. The 

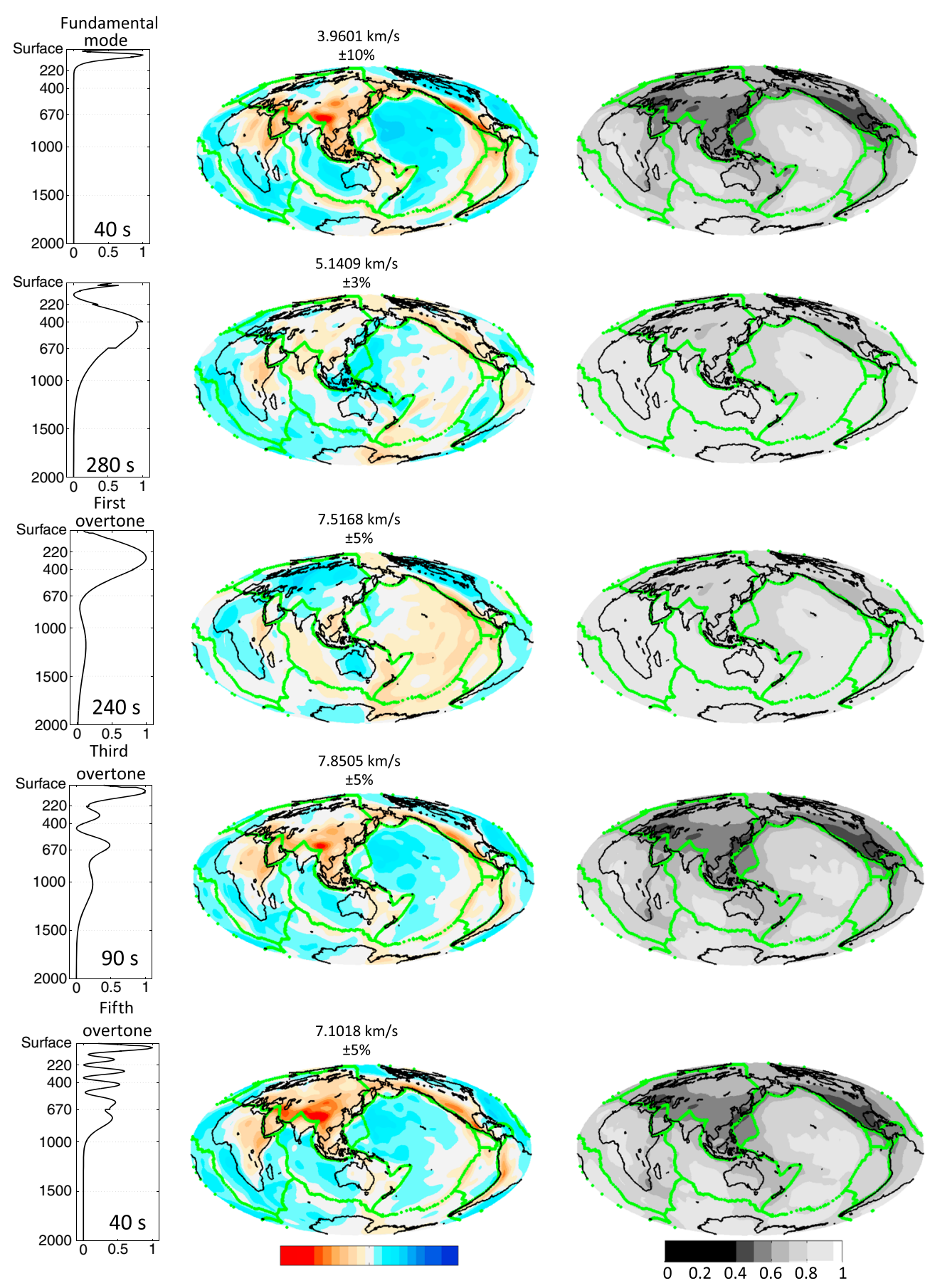

Figure 2. Examples of (middle column) phase velocity maps for some fundamental and higher Rayleigh modes with the corresponding (right column) error maps and (left column) $V_{S}$ sensitivity kernels. Velocity color scales are in percent of a reference value indicated on the top of each map. For the error map shadings, 1 corresponds to an error of $0.05 \mathrm{~km} \mathrm{~s}^{-1}$.

local phase velocity perturbation for mode $m$ and period $T, \delta c_{T}^{m}(\theta, \phi)$, is related to the radial shear velocity structure by:

$$
\delta c_{T}^{m}(\theta, \phi)=\int_{0}^{a} \delta V_{s}(\theta, \phi, r) K_{T}^{m}(r) \mathrm{d} r,
$$

where $\delta V_{s}(\theta, \phi, r)$ is the local shear velocity perturbation at depth $r$ and $K_{T}^{m}(r)=\partial c_{T}^{m} / \partial V_{s}(r)$ the corresponding shear wave sensitivity kernel computed in PREM (see, e.g., Figure 2, left column). This equation implicitly assumes that the compressional velocity $V_{p}$ and the density $\rho$ are not inverted for, which is reasonable as the 


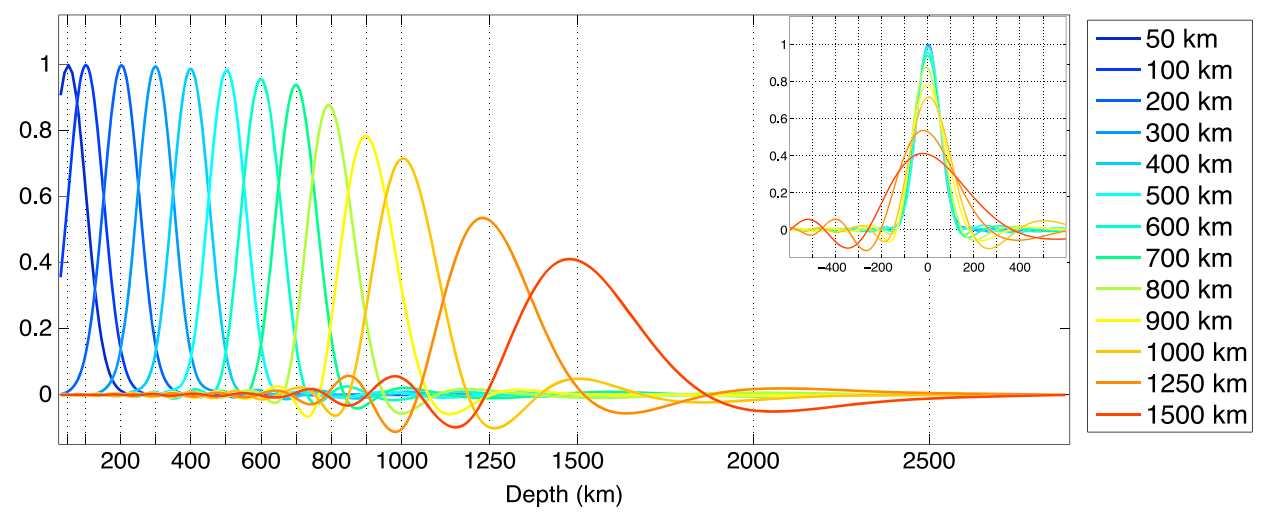

Figure 3. Averaging kernels according to Backus and Gilbert [1968]. Same averaging kernels aligned with respect to their maxima (upper right corner).

Rayleigh waves are mostly affected by $V_{s}$. We also performed an inversion using scaling laws between $V_{s}$ and $V_{p}$ and between $V_{s}$ and $\rho$ and found a shear velocity model almost identical to the one obtained without scaling (see supporting information Figure S3). Thus, we choose to fix $V_{p}$ and $\rho$ to the values of PREM. Before inversion, we perform crustal corrections using phase velocities predicted by the crustal part of the 3SMAC model [Nataf and Ricard, 1996]. The corrected phase velocity maps and the associated errors are given in supporting information Figure S2. The uncorrected data set is shown in supporting information Figure S1.

In order to get an idea of the maximal vertical resolution that we can obtain with our data set, we compute the averaging kernels following Backus and Gilbert [1968]. These averaging kernels, $A\left(r, r_{0}\right)$, relate the model which can be estimated from the inversion, $<m>_{r_{0}}$, to the "true" model, $m(r)$ :

$$
<m>_{r_{0}}=\int_{0}^{a} A\left(r, r_{0}\right) m(r) \mathrm{d} r,
$$

Ideally, we would like $A\left(r, r_{0}\right)=\delta\left(r-r_{0}\right)$ meaning that the data can resolve at each depth an infinitely small length-scale. It is, however, impossible to reach such a resolution with a finite number of data. The resolution kernels $A\left(r, r_{0}\right)$ result from linear combinations of the sensitivity kernels $K_{T}^{m}(r)$. They are computed by minimizing $\left[A\left(r, r_{0}\right)-\delta\left(r-r_{0}\right)\right]^{2}$ [see Backus and Gilbert, 1968]. They are displayed in Figure 3. The shortest resolved length scale increases with depth, ranging from $\sim 50 \mathrm{~km}$ at $100 \mathrm{~km}$ depth to $250 \mathrm{~km}$ at $1500 \mathrm{~km}$ depth. Our data set is barely insensitive to the structure below $1500 \mathrm{~km}$ depth.

To perform the tomographic inversion, we must define the covariances matrices. The a priori data covariance matrix is diagonal and contains the variance calculated from the error maps shown in supporting information Figure S2. The a priori model covariance matrix, $C_{p}$, is nondiagonal: a Gaussian correlation function couples the velocity variations at radii $r$ and $r^{\prime}$ :

$$
C_{p}\left(r, r^{\prime}\right)=\sigma^{2} \exp \left(-\frac{\left(r-r^{\prime}\right)^{2}}{2 L\left(r_{M}\right)^{2}}\right)
$$

where $r_{M}$ is $\left(r+r^{\prime}\right) / 2, L$ the correlation length that controls the vertical smoothness of the model, and $\sigma$ the a priori model standard deviation that controls the amplitude of velocity variations. Based on the results of the averaging kernels, we allow the correlation length $L$ and the a priori model standard deviation $\sigma$ to vary with depth and their values are given in supporting information Table S3.

The shear velocity model obtained from the inversion of our phase velocity maps is displayed in Figure 4 . In the upper mantle, the structures are in general agreement with other recent models derived from fundamental and higher Rayleigh modes [Debayle and Ricard, 2012; Shaeffer and Lebedev, 2013]. For example, we recover the very strong correlation with surface tectonics in the top $200 \mathrm{~km}$, and the high-velocity signature of ponding slabs within the transition zone. However, the addition of longer-period surface waves up to $360 \mathrm{~s}$ provides additional sensitivity down to at least $1000 \mathrm{~km}$ depths. Although these long-period surface waves only constrain the broad-scale structure at the top of the lower mantle, they are very complementary to other existing seismic data sets. They constrain both even and odd degrees of the shear wave mantle structure, 

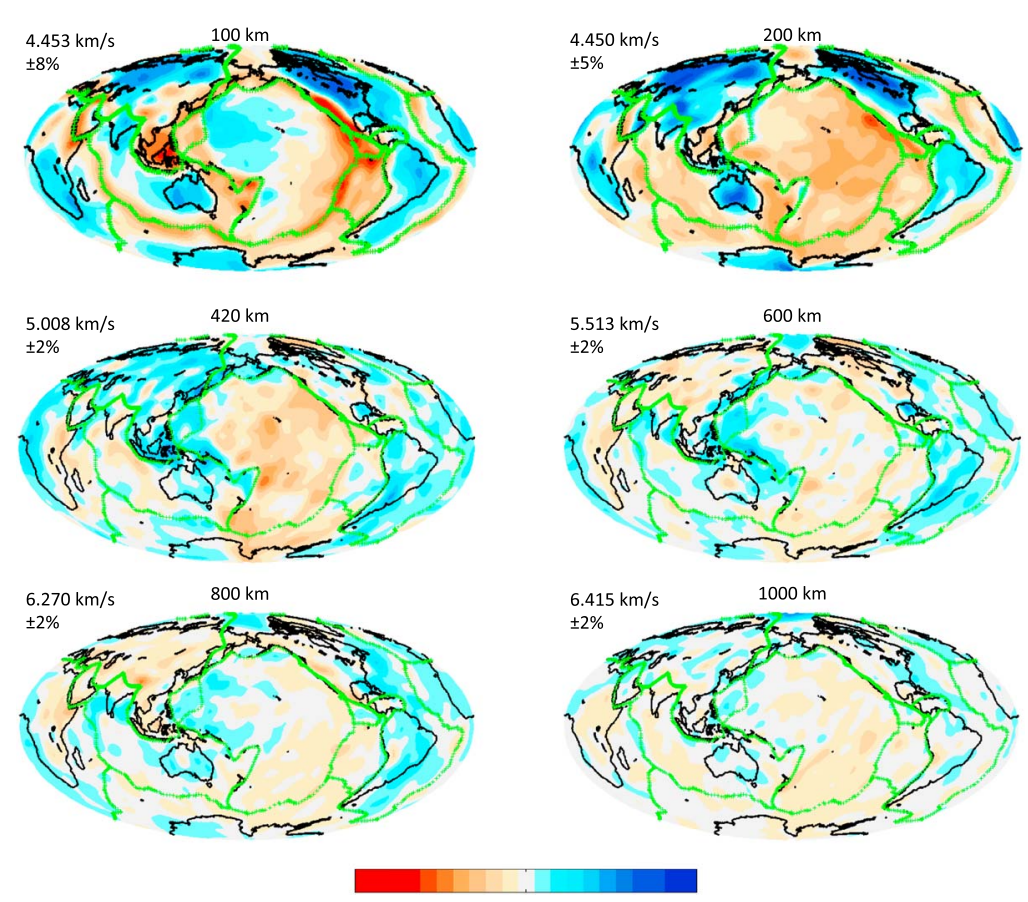

Figure 4. Three-dimensional shear velocity model obtained from the inversion of our phase velocity maps. Color scales are in percent of a reference value indicated on the top left corner of each map.

while normal mode splitting data are only sensible to the even structure. We plan to combine this surface wave data set with normal modes and long-period $S$ wave measurements. This will help to better constrain the mantle broad-scale structure, especially at the top of the lower mantle, where the body wave coverage remains uneven.

\section{Concluding Remarks}

We present a set of fundamental and higher Rayleigh mode phase velocity maps derived from the regionalization of $\sim 22,000,000$ phase velocity measurements. This unique data set has been obtained from the waveform modeling of $\sim 540,000$ waveforms (for a total of 60 periods and 6 modes), following the scheme developed by Debayle and Ricard [2012]. We provide an a posteriori error map associated with each phase velocity map. These error maps can be used to weigh our phase velocity maps in tomographic inversions combining this data set with other seismic data in future global and regional studies. Finally, we show that an inversion of our surface wave data set alone constrains the shear velocity structure down to at least $1000 \mathrm{~km}$ depth. Both the raw measurements and the phase velocity and error maps, with and without crust corrections, are available to the community on request. This data set could be included for the global modeling of the mantle structure, for example, in the recently launched Reference Earth Model initiative.

Acknowledgments This work was supported by the French ANR SEISGLOB ANR-11-BLANC-SIMI5-6-016-01. Our raw measurements and phase velocity maps are freely available on request to stephanie.durand@ens-lyon.fr. We thank Jeroen Ritsema, an anonymous reviewer, and the Associate Editor, Michael Wysession, for their constructive reviews.

The Editor thanks two anonymous reviewers for their assistance in evaluating this paper.

\section{References}

Backus, G., and F. Gilbert (1968), The resolving power of gross Earth data, Geophys. J. R. Astron. Soc., 16(2), 169-205.

Beucler, E., E. Stutzmann, and J.-P. Montagner (2003), Surface wave higher-mode phase velocity measurements using a roller-coaster-type algorithm, Geophys. J. Int., 155(1), 289-307.

Burgos, G., J.-P. Montagner, E. Beucler, Y. Capdeville, A. Mocquet, and M. Drilleau (2014), Oceanic lithosphere-asthenosphere boundary from surface wave dispersion data, J. Geophys. Res. Solid Earth, 119, 1079-1093, doi:10.1002/2013JB010528.

Cara, M. (1979), Lateral variations of S-velocity in the upper mantle from higher Rayleigh modes, Geophys. J. R. Astron. Soc., 57(3), 649-670.

Cara, M., and J. J. Lévêque (1987), Waveform inversion using secondary observables, Geophys. Res. Lett., 14(10), 1046-1049.

Debayle, E. (1999), SV-wave azimuthal anisotropy in the Australian upper mantle: Preliminary results ROM automated Rayleigh waveform inversion, Geophys. J. Int., 137(3), 747-754.

Debayle, E., and Y. Ricard (2012), A global shear velocity model of the upper mantle from fundamental and higher Rayleigh mode measurements, J. Geophys. Res., 117, B10308, doi:10.1029/2012JB009288.

Debayle, E., and M. Sambridge (2004), Inversion of massive surface wave data sets: Model construction and resolution assessment, J. Geophys. Res., 109, B02316, doi:10.1029/2003JB002652.

Debayle, E., B. Kennett, and K. Priestley (2005), Global azimuthal seismic anisotropy and the unique plate-motion deformation of Australia, Nature, 433, 509-512, doi:10.1038/nature03247. 
Dziewonski, A. M., and D. I. Anderson (1981), Preliminary reference Earth model, Phys. Earth Planet. Inter., 25(4), $297-356$.

Ekström, G. (2011), A global model of Love and Rayleigh surface wave dispersion and anisotropy, 25-250 s, Geophys. J. Int., 187(3), 1668-1686.

Ekström, G., J. Tromp, and E. W. F. Larson (1997), Measurements and global models of surface wave propagation, J. Geophys. Res., 102(B4), 8137-8157, doi:10.1029/96JB03729.

Kanamori, H., and D. L. Anderson (1977), Importance of physical dispersion in surface-wave and free-oscillation problems, Rev. Geophys., 15(1), 105-112, doi:10.1029/RG015i001p00105.

Lebedev, S., G. Nolet, and T. Meier (2005), Automated multimode inversion of surface wave and S waveforms, Geophys. J. Int., 162(3), 951-964. Montagner, J. (1986), Regional three-dimensional structures using long period surface waves, Ann. Geophys., 4(B3), $283-294$.

Nataf, H.-C., and Y. Ricard (1996), 3SMAC: An a priori tomographic model of the upper mantle based on geophysical modeling, Phys. Earth Planet. Inter., 95, 101-122.

Nishimura, C. E., and D. W. Forsyth (1989), The anisotropic structure of the upper mantle in the Pacific, Geophys. J. Int., 96(2), $203-229$.

Nettles, M., and A. M. Dziewonski (2008), Radially anisotropic shear velocity structure of the upper mantle globally and beneath North America, J. Geophys. Res., 113, B02303, doi:10.1029/2006JB004819.

Nolet, G. (1975), Higher Rayleigh modes in western-Europe, Geophys. Res. Lett., 2(2), 60-62.

Ritsema, J., H. J. van Heijst, and J. H. Woodhouse (2004), Global transition zone tomography, J. Geophys. Res., 109, B02302, doi:10.1029/ 2003JB002610.

Ritsema, J., A. Deuss, H. J. van Heijst, and J. H. Woodhouse (2011), S40RTS: A degree-40 shear velocity model for the mantle from new Rayleigh wave dispersion, teleseismic traveltime and normal-mode splitting function measurements, Geophys. J. Int., 184(3), $1223-1236$.

Ritzwoller, M. H., and A. L. Levshin (1998), Eurasian surface wave tomography: Group velocities, J. Geophys. Res., 103(B3), 4839-4878, doi:10.1029/97JB02622.

Shaeffer, A. J., and S. Lebedev (2013), Global shear speed structure of the upper mantle and transition zone, Geophys. J. Int., 194(1), 417-449.

Stutzmann, E., and J.-P. Montagner (1993), An inverse technique for retrieving higher mode phase-velocity and mantle structure, Geophys. J. Int., 113(3), 669-683.

Tarantola, A., and B. Valette (1982), Generalised nonlinear inverse problems solved using the least square criterion, Rev. Geophys., 20(2), 219-232, doi:10.1029/RG020i002p00219.

Trampert, J., and J. H. Woodhouse (1995), Global phase velocity maps of Love and Rayleigh waves between 40 and 150 seconds, Geophys. J. Int., 122(2), 675-690.

van Heijst, H., and J. Woodhouse (1997), Measuring surface-wave overtone phase velocities using a mode branch stripping technique, Geophys. J. Int., 131(2), 209-230.

van Heijst, H., and J. Woodhouse (1999), Global high-resolution phase velocity distributions of overtone and fundamental-mode surface waves determined by mode branch stripping, Geophys. J. Int., 137(3), 601-620.

Visser, K., S. Lebedev, J. Trampert, and B. L. N. Kennett (2007), Global Love wave overtone measurements, Geophys. Res. Lett., 34, L03302, doi:10.1029/2006GL028671.

Visser, K., J. Trampert, and B. L. N. Kennett (2008), Global anisotropic phase velocity maps for higher mode Love and Rayleigh waves, Geophys. J. Int., 172(3), 1016-1032.

Yoshizawa, K., and B. Kennett (2002), Determination of the influence zone for surface wave paths, Geophys. J. Int., 149(2), $440-453$. 